This is an electronic reprint of the original article. This reprint may differ from the original in pagination and typographic detail.

Author(s): Freedman, Justin E.; Honkasilta, Juho

Title: Dictating the boundaries of ab/normality : a critical discourse analysis of the diagnostic criteria for Attention Deficit Hyperactivity Disorder and Hyperkinetic Disorder

Year: $\quad 2017$

Version:

Please cite the original version:

Freedman, J. E., \& Honkasilta, J. (2017). Dictating the boundaries of ab/normality : a critical discourse analysis of the diagnostic criteria for Attention Deficit Hyperactivity Disorder and Hyperkinetic Disorder. Disability and Society, 32(4), 565-588.

https://doi.org/10.1080/09687599.2017.1296819

All material supplied via JYX is protected by copyright and other intellectual property rights, and duplication or sale of all or part of any of the repository collections is not permitted, except that material may be duplicated by you for your research use or educational purposes in electronic or print form. You must obtain permission for any other use. Electronic or print copies may not be offered, whether for sale or otherwise to anyone who is not an authorised user. 
Dictating the boundaries of ab/normality: a critical discourse analysis of the diagnostic criteria for Attention Deficit Hyperactivity Disorder and Hyperkinetic Disorder

Justin E. Freedman

Department of Teaching and Leadership, Syracuse University, Syracuse, New York, United States of America

Address: Syracuse University, 150 Huntington Hall, Syracuse, New York, 13210

Phone Number: 016096105455

and

Juho M. Honkasilta

Department of Education, University of Jyväskylä, P.O.Box 35, FI-40014 University of Jyväskylä, Finland

Please direct all correspondence to Justin E. Freedman at jefreedm@syr.edu 


\section{Dictating the boundaries of ab/normality: a critical discourse analysis of the diagnostic criteria for Attention Deficit Hyperactivity Disorder and Hyperkinetic Disorder}

In this paper, we report the findings of a critical discourse analysis of the diagnostic criteria for Attention Deficit Hyperactivity Disorder (ADHD) and Hyperkinetic Disorder (HD) in two clinical manuals - the Diagnostic and Statistical Manual of Mental Disorders, $5^{\text {th }}$ edition and International Classification of Diseases, $10^{\text {th }}$ edition. We examine the actions (behaviors) that are said to indicate the presence of ADHD/HD and analyze what the inclusion of these actions reveals about the relationship between ADHD/HD, cultural knowledge and values. Our analysis reveals that both manuals use subjective, value-laden language to construct a mentally ill individual in opposition to an unseen, supposedly 'normal' person. We argue that the current criteria draw into question whether ADHD/HD meets the manuals' own definitions of a disorder and further, that the discourse of the manuals are intertwined with the everyday practices of schools and serve to legitimize status quo educational practices.

Keywords: Attention Deficit Hyperactivity Disorder; Hyperkinetic Disorder; critical discourse analysis; clinical manuals.

\section{Points of interest}

- Attention Deficit Hyperactivity Disorder (ADHD) and Hyperkinetic Disorder (HD) are controversial disorders, diagnosed in many countries.

- Children sometimes get labelled with a disorder, often when they are being too lively or because they do not concentrate for long on their play or school work.

- We begin with one such child and then examine the specific behaviors that are said to indicate ADHD and HD in two clinical manuals: Diagnostic and Statistical Manual of Mental Disorders, $5^{\text {th }}$ edition and International Classification of Diseases, $10^{\text {th }}$ edition.

- While the manuals claim to describe illness, most of the symptoms actually describe culturally deviant behavior, drawing into question whether ADHD/HD meets the manuals' own definitions of a disorder.

- Because the criteria frame difficulties in school as individual mental illness, it shifts the burden away from schools to alter their structures and practices in ways that will support the diversity of students. 


\section{Introduction}

Seven-year-old Alex is playing alone in a room. He is noisy and active. He plays with action figures, leaves them after a while because he finds cushions and other material to build a fort until, again, he finds more attractive things to do. He continuously changes between toys and activities, as no toy or activity engages his attention for longer than a few minutes. After 30 minutes, the room is a mess, but Alex seems happy. Later on, Alex enters the room again. This time, hidden cameras are installed in the room so that adults can observe his play. Alex engages in a similar pattern of activity. Once again, the room is a mess, and Alex seems pleased. Now, however, he appears to be manifesting symptoms of Attention Deficit Hyperactivity Disorder (ADHD) - the most commonly diagnosed psychiatric disorder of childhood and adolescents in many countries, characterized by deficits in regulating attention, activity and impulsivity (APA 2013, 59-66).

This hypothetical scenario drawn from previous research settings ${ }^{1}$ does not aim to explain the nature of ADHD, but instead to illustrate how energetic, noisy, and spontaneous play becomes recontextualized as symptoms of a mental disorder, namely ADHD (APA, 2013) and its European counterpart Hyperkinetic Disorder (HD) (WHO, 1993a). ${ }^{2}$ By recontextualization, we refer to how behaviors can have certain meanings in one context - or specific setting - but take on entirely new meanings in another context (van Leeuwen 2009). Alex's behavior becomes recontextualized when evaluated through the lens of the professional knowledge domain of

\footnotetext{
${ }^{1}$ This hypothetical scenario was created with consideration of previous studies in which children diagnosed with ADHD were videotaped in controlled situations by researchers who studied their behavior in order to test hypotheses associated with features of ADHD (e.g., Antrop et al 2000; Antrop et al 2005).

${ }^{2}$ We refer to Attention Deficit Hyperactivity Disorder and Hyperkinetic Disorder as a singular disorder, written as "ADHD/HD" throughout the paper. We do so because ADHD and HD are generally understood to refer to the same cluster of behaviors and efforts to harmonize the criteria for both are ongoing (APA 2013). However, there are differences in both the diagnostic criteria and clinical outcomes of ADHD and HD. We address these differences later in the paper.
} 
mental health and behavioral specialists. This recontextualization of behavior as discourses of normality and disability is only possible through the presence of observers who are familiar with a certain discourse about mental health and illness that is based in historically rooted ideas about what it means to be a 'normal' child in the Western world (Cooper, 2013). This recontextualization is imbued with cultural values about ab/normality and dis/ability and is validated through diagnostic guidelines presented in clinical manuals of psychiatric disorders such as '[o]ften unable to play or engage in leisure activities quietly' (APA 2013, 60) and '[o]ver frequent changes between activities when choice is allowed' (World Health Organization 1993a, 190). Interpreting these behaviors as potentially symptomatic is no small matter, because diagnostic guidelines quite literally designate the boundaries between health and illness.

Rates of diagnosis of ADHD/HD have risen significantly around the world over the last few decades, to an extent that Timimi $(2004,8)$ has called 'epidemic proportions.' There has been no shortage of explanations for this trend, many of which have theorized culture differences in the way teachers, parents, and the medical professionals respond to different children (e.g. Timimi 2004, Graham, 2010a). Interestingly, the rise of ADHD/HD has occurred despite the fact that it is a disorder without identifiable organic pathology. It is typically diagnosed using rating scales or checklists, because there is no method or test that shows conclusive, 'hard' evidence that $\mathrm{ADHD} / \mathrm{HD}$ exists inside one person but not another, and neither is there clear evidence for a cause of the disorder (Nigg 2006). This is by no means unusual in the field of psychiatry. A lack of identifiable etiology for mental disorders has long been a problem in psychiatry and has contributed to controversies over the validity of many disorders (Townsend 1982).

Yet while ADHD/HD has not achieved etiological validity, it is widely considered a clinically valid psychiatric entity (Faraone 2005). A disorder may be understood as clinically 
valid if it "hangs together statistically (as a syndrome), is exhibited by impaired children who need help, responds to treatment, and has other meaningful external correlates $[\ldots]$ at the group level” (Nigg, 2006, 4). In a practical sense, clinical validity can only be achieved if certain behaviors are recognized as symptomatic of mental disorder. Therefore, the decision to include certain behaviors and not others in the diagnostic criteria of clinical manuals is instrumental in achieving clinical validity (WHO 1993a, 188). If the validity of ADHD/HD rests largely upon the frequent recognition of symptomatic behaviors, then it is necessary to closely examine the very behaviors which are said to indicate the disorder.

In this article, we seek to contribute to literature that places "psychiatric theories in their social and political context" (Moloney 2010, 136). Building on previous sociocultural analyses of mental disorders, such as those of hyperkinetic disorder (Conrad 1975) and Obsessive Compulsive Disorder (Davis 2008), we analyze how dis/ability and ab/normality are constructed in the diagnostic criteria of clinical manuals that define ADHD/HD, namely Diagnostic and Statistical Manual of Mental Disorders, 5th. Edition (DSM-5) by the APA (2013) and International Classification of Disorders, 10th. Edition (ICD-10) by the World Health Organization (WHO 1993a). We are guided by the following research questions: how are certain actions (behaviors) portrayed to indicate the presence of ADHD/HD in the DSM-5 and ICD-10; and what does the inclusion of these specific actions in clinical manuals for mental disorders tell us about the relationship between $\mathrm{ADHD} / \mathrm{HD}$, cultural knowledge, and social values?

In this article, we illustrate that the actions described as symptomatic of a mental disorder are highly dependent upon culturally specific knowledge that is often unstated or implied in the manuals, and in turn draw into question whether $\mathrm{ADHD} / \mathrm{HD}$ meets the manuals own definitions of a disorder. Further, we argue that the discourse of the manuals both reflect and reproduce 
institutional practices predicated on specific values and norms that are intertwined with the everyday practices of schools and may function to legitimize status quo educational practices.

\section{The divisive discourse of ADHD/HD: a struggle for legitimization}

We begin by providing some context about the larger discourse of ADHD/HD. Van Dijk (2014) argues that individuals and groups struggle to legitimize their knowledge in order to establish a dominant viewpoint in the broader discourse of a particular topic. Since the formalization of $\mathrm{ADHD} / \mathrm{HD}$ as a mental disorder, ${ }^{3}$ an epistemological struggle has ensued over the nature of the so-called disorder (for an outline, see the debate between Barkley [2002; 2004] and Timimi [2004]). Many researchers have argued that ADHD/HD is primarily a socially constructed disorder that tells us much more about society than about diagnosed individuals (e.g. Lloyd, Stead, Cohen et al. 2006; Timimi and Leo et al. 2009; Graham 2010a; Saul 2014). However, the main brokers of ADHD/HD's epistemological community - medical scientists in the fields of psychology, psychiatry, and neurology - have overwhelmingly dismissed dissenting voices in the discourse, instead seeking to legitimize their knowledge about the validity of ADHD/HD. Proponents of the ADHD/HD medical construct have framed their role as correcting misinformation. For example, in books aimed at both laypersons and clinicians, it is common to find chapters which aim to dispel 'myths' or 'fictions' about ADHD/HD for the reader, such as '35 Myths about ADHD and Why they are Wrong' by Brown (2013) (for another example, see Barkley 2013), thereby asserting what is true according to the scientific 'experts.' Advocacy groups also attempt to reveal 'myths' about ADHD/HD via their websites (for example, Children and Adults with ADHD 2015).

\footnotetext{
${ }^{3} \mathrm{ADHD} / \mathrm{HD}$ first appeared in the $2^{\text {nd }}$ edition of the DSM in 1968 (then called "hyperkinetic reaction of childhood") and in the $9^{\text {th }}$ edition of the ICD in 1977 (then called "hyperkinetic syndrome of childhood", Sharkley and Fitzgerald 2007). One of the earliest and often cited critiques of ADHD/HD was Conrad (1975) who argued that the advent of the disorder signaled the medicalization of otherwise healthy behavior in children.
} 
A common tactic used by those who wish to establish a dominant position within a contentious discourse is to present themselves as rational, objective, and non-ideological through the use of scientific rhetoric (Wodak and Meyer 2009).This tactic is commonplace in the discourse on ADHD/HD and is perhaps best illustrated by the International Consensus Statement on ADHD (Barkley et al. 2002), published in the Clinical Family and Child Psychology Review. Edited by the widely published US psychiatrist Russell Barkley, this two-page statement is signed by 86 doctors from nine countries, with an overwhelming majority from the United States and Canada. Self-identifying as 'leading international scientists,' the authors use the words 'science' or 'scientific' a total of 19 times in the two page document. The only subheading of the statement reads simply 'ADHD and Science,' and its first sentence reads that ADHD's existence is a 'matter of science' $(2002,89)$.

Despite offering no in-text citations to corroborate their claims, the authors assert that claiming that $\mathrm{ADHD}$ is not a legitimate medical disorder is 'tantamount to declaring the earth flat, the laws of gravity debatable, and the periodic table in chemistry a fraud' (Barkley et al. 2002, 90). The authors assertively juxtapose their knowledge to non-scientific knowledge (e.g. media accounts) that challenges the validity of $\mathrm{ADHD}$, implying that the only counterpoints to their own are based on unscientific, and thus illegitimate, knowledge. While the authors' attempt to outright stifle any future debate about the existence of ADHD/HD has been criticized for being incongruent with the spirit of scientific inquiry (Jureidini 2002), it is not altogether surprising from the viewpoint of discourse studies; like many discourses, the discourse surrounding ADHD/HD is rife with examples of individuals and groups who strive to establish their worldview as an objective truth and in turn, attempt to dictate what counts as legitimate 
knowledge about ADHD/HD. Despite the 2002 consensus statement, critiques about the validity of ADHD continue internationally (e.g., Moncrieff and Timimi 2010; Whitely 2015).

In this article, we move beyond a discussion about the 'truth' of $\mathrm{ADHD} / \mathrm{HD}$ - that is, whether it exists. Following Davis (2009), we begin by accepting that disorders exist insofar as they are recognized as legitimate in discursive practices within social, cultural, and institutional contexts. The existence of ADHD/HD is promoted by medical scientists and accepted by laypersons (e.g., parents) and pertinent professionals (e.g., teachers) in their everyday practices. In other words, $\mathrm{ADHD} / \mathrm{HD}$ exists because it is inscribed in clinical manuals, diagnosed by physicians, and commonly recognized by laypeople as a valid mental disorder. Instead of asking whether the disorder exists, we seek to illuminate the actions that are depicted as legitimate indicators of $\mathrm{ADHD} / \mathrm{HD}$ within the discourse of medical science.

\section{Definitions and guidelines of diagnosing ADHD/HD}

While the DSM has been criticized for employing highly subjective criteria in its delineation of what constitutes mental illness (Kirk and Kutchins 1992; British Psychological Society 2011), and for the financial ties between DSM committee members and the pharmaceutical industry (Cosgrove, Krimsky, Vijayaraghavan and Schneider 2006), the manual remains the primary diagnostic manual of mental disorders in large countries such as the United States and Australia, leading us to choose it as a text for our analysis (Al-Yagon et al. 2013). ADHD is listed under "Neurodevelopmental Disorders" and defined in the DSM-5 as 'a persistent pattern of inattention and/or hyperactivity-impulsivity that interferes with functioning or development' (APA 2013, 59). Several changes were made to ADHD diagnostic criteria in the revised DSM-5, including raising the maximum age at which symptoms must have been present 
and elaborating symptomatic behaviors. Given these changes, it is expected that rates of ADHD diagnoses will continue to rise (Sibley et al. 2013).

Widely used in European countries such as Germany and the United Kingdom, the World Health Organization's ICD-10 does not include the term ADHD, but instead uses Hyperkinetic Disorder (Al-Yagon et al. 2013). HD is listed under 'behavioral and emotional disorders with onset usually occurring in childhood and adolescence,' and is defined as 'a combination of overactive, poorly modulated behaviour with marked inattention and lack of persistent task involvement' (WHO 1993a, 206). Both the DSM-5 and ICD-10 report that ADHD/HD begins in childhood while sometimes persisting into adulthood. Both manuals also state that symptoms must be present in more than one setting.

There are several differences between the criteria of ICD-10 and DSM-5. First, as is evident, the disorders have different names. While the authors of ICD-10 write that attention is a central aspect of the disorder, they choose not to use the term ADHD 'because it implies a knowledge of psychological processes that is not yet available' (206). Another difference is in the perceived severity of the disorders. It has been suggested that in clinical practice, broader criteria set forth in the DSM-5 are a factor in higher rates of diagnosis than in countries using the ICD-10, which employs narrower criteria, suggesting a more 'severe' form of ADHD (Lee et al. 2008). Lahey and colleagues (2006) warn of the potential for under-detection of ADHD symptoms using the comparatively stricter ICD-10 criteria. However, it is likely that the diagnostic criteria of $\mathrm{ADHD} / \mathrm{HD}$ will come to more closely resemble each other because there is an ongoing effort to harmonize the forthcoming ICD-11 with the DSM-5 (APA 2013, 11).

\section{Theoretical Framework}


We base our analysis of behaviors said to constitute ADHD/HD on the framework of discourse studies. In general, discourse refers to both 'recurrent statements and wordings across texts' (Luke 1995, 15), and also to language as a form of social practice (Fairclough 1995). Put another way, discourse can be understood as a 'systematically organized set of statements which give expression to the meaning and values of an institution' (Kress 1985, 6, as quoted in Rogers 2004, 5). As an interdisciplinary field, discourse studies is 'concerned with the systematic theory and analysis of discourses and their various contexts' (Van Dijk 1981, 1). Discourse studies can thus be used as a theoretical approach aimed at highlighting the relationship between texts, institutions, and social practices.

Within the broader discipline of discourse studies, we approach this analysis from the related framework of Critical Discourse Studies (CDS). A distinguishing element between discourse studies and CDS is its 'critical' orientation. While examining discourse attends to the use of language in social practices, CDS leads to critical analyses of these practices by focusing on the power exercised by social institutions, including the strategic deployment of ideology through texts (Rogers 2004). In examining the diagnostic criteria for ADHD/HD in tDSM-5 and ICD-10, we are concerned with gaining an 'understanding of how language functions in sustaining and transmitting knowledge, in organizing social institutions or in exercising power' (Wodak and Meyer 2009, 7).

To do so, we examine a specific discourse genre - clinical manuals. By genre, we refer to what Fairclough $(1995,14)$ describes as 'a socially ratified way of using language in connection with a particular type of social activity.' In this case, the manuals are connected to the social activity of clinical diagnoses; the manuals are explicitly intended to shape the everyday practice clinicians who examine patients. The DSM and ICD are products of professional 
organizations in the psy-medical sciences that are intended to coach clinicians into certain ways of interpreting behavior and what constitutes 'impairment' and 'harm' in patients. The content of the DSM-5 and ICD-10 also reaches beyond clinicians and influences other institutional practices as well, such as how schools respond to individuals. For example, some textbooks used in teacher education programs in the United States include the diagnostic criteria for ADHD, taken directly from DSM (Freedman 2016). Other similar diagnoses such as Oppositional Defiance Disorder (ODD) (DSM-5) and Conduct Disorder (CD) (ICD-10), become justification for school-based disability labels such as 'emotional disability' or 'emotionally disturbed.'

\section{Method}

We conducted a Critical Discourse Analysis (CDA) of the diagnostic criteria for ADHD/HD in two clinical manuals. We chose CDA as our method of inquiry because it provides us with analytical tools to examine textual data in an attempt to show the relationship between language, ideology, and power (Fairclough 1995). Further, CDA allows us to examine data 'as evidence of social processes' which potentially reveal the unarticulated relationship between language and institutional practices with regards to ADHD/HD (Widdowson 1995, 159). We draw upon CDA as an attempt to make sense of ADHD/HD as a social phenomenon by showing how language is used to construct a subject, namely the individual depicted as having ADHD/HD. Guided by van Leeuwen (2009), we approach the data as an analysis of actions - the things people must do in order to be considered to have ADHD/HD. Additionally, our analysis goes beyond examining the actions said to constitute the disorder to an analysis of how the authors of the manuals use certain linguistic methods to depict ADHD/HD. Both what is said and how it is said are key in understanding how the authors transform actual practices of a 
context by describing them as potentially symptomatic actions in a new context (i.e. clinical manuals), and thus recontextualize the action.

\section{Data Sources}

The data analyzed in this study consists of the diagnostic criteria for ADHD and HD. Data are taken from two sources. Criteria for ADHD were taken from the most recent addition of the DSM (5th edition, APA 2013). All data for ADHD can be found under the section entitled 'Attention Deficit Hyperactivity Disorder' (2013, 59-66) which appears in the chapter entitled 'Neurodevelopmental Disorders.' The criteria examined in this section are 18 symptoms, nine of which are listed under the subsection 'Inattention' and nine of which are listed under the subsection 'Hyperactivity and Impulsivity' (see Appendix A). For HD, all data were taken from the ICD-10 (WHO 1993a), which was accessed online at the website of the World Health Organization. The information addressing HD can be found in the sub-manual entitled ICD-10 Classification of Mental and Behavioural Disorders - Diagnostic criteria for research. All of the 22 symptoms can be found under the subsection entitled 'Hyperkinetic Disorder' (1993a, 188190, see Appendix B).

\section{Data Analysis}

In order to analyze the actions (behaviors) in the manuals, we ask three questions of the data that are rooted in the field of CDA, and which serve as the themes of the results section. First, discourse is dependent on shared knowledge between the author and reader, or what Van Djik $(2014,145)$ calls, sociocultural knowledge, that is, shared ideas or beliefs that form the common ground which makes stated ideas sensible to a reader within a given context. We therefore ask: what is the sociocultural knowledge needed by the reader to make sense of the actions as symptoms of a mental disorder? Second, discourses reflect power inequalities in 
society, because certain epistemic communities produce knowledge which frames the actions of some individuals or groups as a problem (Wodak and Meyer 2009). We therefore ask: how do the manuals construct the subject of the text as a problem (e.g., as deviant or ill)? Lastly, as Van Dijk (2014) notes, epistemic communities adhere to their own criteria for producing knowledge that often goes unstated, thus masking the values underpinning the discourse. We therefore ask, what values or worldviews are implicit in the actions described in the manuals? Using these three questions for analysis, the authors independently coded the 18 symptoms listed under diagnostic criteria for ADHD in DSM-5, followed by independently coding the 22 symptoms listed under diagnostic criteria for HD in ICD-10. After conferring, we found that several of the same symptoms were coded across multiple questions and are included as such in the results.

\section{Results}

What is the sociocultural knowledge needed by the reader to make sense of the actions as symptoms of a mental disorder?

If discourse requires shared knowledge between the author and reader, then all actions described in the manual are dependent upon knowledge that is specific to sociocultural circumstances. In the manuals, the assumed shared knowledge is evident in the use of ambiguous language describing the frequency with which behaviors must occur to be considered symptomatic. For example, each of the 18 symptoms listed in the DSM-5 diagnostic criteria for ADHD begin with the descriptor 'often' or 'is often':

- is often forgetful in daily activities (APA 2013, 59)

- often fidgets with or taps hands or feet or squirms in seat (APA 2013, 60)

The ICD-10 authors use a wider variety of frequency and degree of severity descriptors, including 'often,' 'very often,' 'excessive,' 'markedly' and 'unduly.' Examples include the following: 
- unduly high distractibility during study e.g. homework or reading assignment (WHO 1993a, 189)

- excessive levels of off-task activity during tasks (WHO 1993a, 190)

Without any descriptions of the threshold for what constitutes 'often' or 'excessive,' the authors rely on the reader sharing a sociocultural understanding of the meaning of these descriptors (Abbey and Valsiner 2005). The reliance on vague descriptors in the criteria for $\mathrm{ADHD} / \mathrm{HD}$ is of particular importance given that there is no definitive marker for the presence of ADHD/HD inside an individual (Nigg 2006). Determining who "has" ADHD/HD is therefore dependent on shared cultural understandings of how much of a certain behavior is too much (i.e. occurs too 'often') and in which context, such that it is judged to be impairing and assumed to indicate the presence of a mental disorder.

Despite using vague descriptors, one way that the authors bridge the sociocultural knowledge needed to make sense of the actions is by contextualizing them in social settings. For example, the ICD-10 divides its symptoms into two contexts: at home and at school or nursery. Examples of behaviors in these contexts include the following:

- markedly excessive activity in situations expecting relative stillness (e.g., mealtimes, travel, visiting, church) (Who 1993a,189)

- markedly excessive fidgeting and wriggling in structured situations (WHO 1993a, 190)

In naming the setting (i.e., home or school) the authors suggest that these behaviors occur through the interaction between individuals and environments with specific expectations such as 'situations expecting relative stillness' and 'structured situations' (189-190). DSM-5 lists similar symptoms but does not separate symptoms according to the environment in which they occur and often describes actions without identifying the context or expectations of the environment. For example, the symptom "often unable to play or engage in leisure activities quietly (APA 2013, 
60)" is included with no mention of the environment in which these play activities occur nor why the short duration would be problematic.

In both manuals, there is no mention of the actor (presumably a teacher or parent) who would potentially find these behaviors to be a problem. Instead, the symptoms seemingly emerge from nowhere, divorced from any specific cultural expectations. This is a glaring omission, given that the knowledge of norms of specific contexts is needed to understand why, for example, "often fidgets with or taps hands or feet or squirms in seat" (DSM-5; APA 2013, 60) is a problem in the first place. The reader must possess cultural knowledge that certain structured situations require stillness, in which case movement violates the expectations of these contexts.

These examples illustrate the process of deletion when describing actions; the authors describe behaviors as symptoms by leaving out either the norms or actors that are germane to the specific context (van Leeuwen, 2009). In the earlier DSM-5 example above, "Often unable to play or engage in leisure activities quietly", the authors delete the presence of both actors and any explanations of norms that place a value on quietness in a specific environment. In the latter example above, "Often has difficulty waiting his or her turn," there is no mention of the individuals with whom the person is interacting, and only a vague reference to the social situation of waiting in line (APA 2013, 60). Again, the authors delete other actors and offer an amorphous, decontextualized group of descriptors which leave the reader to rely on a general sociocultural knowledge that waiting in line is a preferred behavior, and that those who do not do so may have a mental disorder.

How do the manuals construct the subject of the text as a problem (e.g. as deviant or ill)?

In describing the behaviors said to indicate the presence of a mental disorder, the manuals construct a subject - an individual who is said to have ADHD/HD, but also, whose behaviors are 
problematic. After all, if these behaviors were not deemed to be problematic, or deviant, they would not exist in the manuals in the first place. Individuals' behaviors gain meaning as problems in reaction to social circumstances and interactions with others. We identified two types of reactions described in the data: reactions to contextual demands and reactions to the expectations of other social actors.

Reactions to contextual demands consist of descriptions of behavior that are in response to expectations of a given social context. These can be found in several instances in both DSM-5 and ICD-10, for instance:

- Often leaves seat in situations when remaining seated is expected (e.g., leaves his or her place in classroom, in the office or other workplace, or in other situations that require remaining in place) (DSM-5; APA, 60)

- Often runs about or climbs in situations where it is inappropriate (Note: In adolescents or adults, may be limited to feeling restless) (DSM-5; APA, 60, original emphasis)

- Very often runs about or climbs excessively in situations where it is inappropriate; seems unable to remain still (ICD-10; WHO 1993a, 189)

In these above examples, the use of the terms 'expected' and 'inappropriate' makes clear that the behaviors are being evaluated in relation to what is expected of the individual (e.g. children remaining seated at their classroom desks). These examples highlight how it is not the reactions themselves, but the conflict with social expectations, that give meaning to these actions as problems. For example, 'leaves seat' is itself not a symptomatic behavior, but is only understood as one if it occurs 'in situations when remaining seated is expected.' Similarly, the actions of running and climbing cannot be understood as symptoms without the clause 'in situations where it is inappropriate.' In constructing these behaviors as deviant, the authors dictate the boundaries of appropriate behavior and do so without any specific discussion of the logic underlying these contextual norms. 
The second type of reaction we identified is reactions to the expectations of other social actors. Unlike the previous examples in which actions are described in relation to social expectations, reactions to social actors include instances in which the behavior is in interaction with another actor(s) or group(s). Examples include:

- Undue lack of persistence at tasks set by adults (ICD-10, 188)

- Often interrupts or intrudes on others (e.g. butts in to others' conversations or games) (ICD-10, 189)

- Often interrupts or intrudes on others (e.g. butts in to others' conversations or games, or activities; may start using other people's things without asking or receiving permission; for adolescents and adults, may intrude into or take over what others are doing) (DSM-5, $60)$

- Often blurts out an answer before question has been completed (e.g., completes people's sentences; cannot wait for turn in conversation) (DSM-5, 60)

In these examples, the symptomatic behavior is constructed in direct relation to the presence of others (e.g., interrupts or intrudes on others). The use of the term "task set by adults" invokes an implied power relation between the subject and another person. It is implicitly suggested that the individual should persist in completing tasks because adults are wise enough to select appropriate tasks. The subject is also constructed as a potential menace to others - an intruder. Underlying these behaviors is the privileging of certain kinds of interactions - waiting one's turn for instance - that are commonly expected in environments such as classrooms. Other types of interactions, such as deviating from tasks or directions set by adults, are also constructed as indicators mental disorder.

In other instances, actions are framed as a problem in relation to non-disabled individuals. In two instances in the DSM-5, behaviors listed highlight the inability of a supposedly healthy individual. For example, under the list of hyperactivity symptoms, individuals are described as often 'on the go,' (60) and "difficult to keep up with" (60) (emphasis added). Additionally, in the diagnostic features section of the DSM-5, the authors write that '[i]n adults, hyperactivity may 
manifest as...wearing others out with their activity' (61, emphasis added). The authors, perhaps unwittingly, acknowledge the inability of the non-disabled individual to 'keep up' and the tendency for their 'wearing...out' in relation to the individual said to have ADHD/HD. Rather than citing these behaviors of the non-disabled individual as shortcomings, they are used to pathologize the individual with ADHD/HD. Following Levy and colleagues (1997), it seems that the actual criterion being used here is the annoyance threshold of the observer or other social actor; observed behavior becomes tied to the motivation or emotion of the observer, and thus, is reconstructed as a symptom manifestation of the one being observed.

What values or worldviews are implicit in the actions described in the manuals?

In describing what constitutes disorderly behavior, the manuals delineate the kinds of actions that are considered appropriate behaviors. Underlying these distinctions are certain worldviews about the ways individuals should act, which reflect value judgments that are not stated explicitly. In Table 1 presents four values that are evident in the behaviors described by the authors. These values are perseverance, stillness, social intelligence, and organization. Table 1. Values evident in ADHD/HD criteria

\begin{tabular}{|c|c|}
\hline Value & Examples of Diagnostic Criteria \\
\hline Perseverance & $\begin{array}{l}\text { - Often leaving play activities unfinished (ICD-10,188) } \\
\text { - Undue lack of persistence at tasks set by adults (ICD-10, 188) } \\
\text { - Often has difficulty sustaining attention in tasks or play activities } \\
\text { (DSM-5, 59) }\end{array}$ \\
\hline Stillness & $\begin{array}{l}\text { Markedly excessive fidgeting \& wriggling during spontaneous } \\
\text { activities (ICD-10, 189) } \\
\text { Markedly excessive fidgeting and wriggling in structured situations } \\
\text { (ICD-10,190) } \\
\text { Often fidgets with or taps hands or feet or squirms in seat (DSM-5, } \\
\text { 60) }\end{array}$ \\
\hline $\begin{array}{l}\text { Social } \\
\text { intelligence }\end{array}$ & $\begin{array}{l}\text { - Often has difficulty awaiting turns in games or group situations (ICD- } \\
10,189 \text { ) } \\
\text { - Often talks excessively (DSM-5, 60) } \\
\text { - Often interrupts or intrudes on others (DSM-5, 60) }\end{array}$ \\
\hline Organization & Often has difficulty organizing tasks and activities (DSM-5, 59) \\
\hline
\end{tabular}


- Often loses things necessary for tasks and activities (DSM-5, 59)

An emphasis on perseverance is reflected in the authors' emphasis on completing one task before moving to another. The implicit worldview underlying these behavioral indicators is that supposedly healthy or normal individuals thoroughly complete tasks, one at a time. The importance of stillness is evident in the authors' pathologzing of certain movements, such as fidgeting, wriggling, and squirming. Here, the authors equate what they depict as unproductive or unnecessary movements, with illness. The importance of social intelligence, the skill of navigating social situations, is also emphasized in manuals. Returning to the concept of the annoyance threshold, the characteristics of social intelligence are dependent on what may bother the supposedly healthy individual (e.g., someone that talks too much, or impedes their participation in an activity). In this sense, the authors privilege behavior that is less likely to be interpreted as rude or irritating.

Organization is the focal point of two behavioral descriptors of inattention in the DSM-5, but is not a theme found in the ICD (Table 1). Some specific examples listed next to these symptoms are difficulty managing sequential tasks; messy, disorganized work; and the tendency to lose school or other materials such as pencils, books, and keys (DSM-5, 59). Here the authors of the DSM emphasize the importance of maintaining organization with regards to time and physical objects. Certainly many teachers are familiar with students who do not come to class prepared with their books, and many adults have experienced losing their keys frequently. Yet, the emphasis on skill-set shows the bias of the authors towards certain abilities, particularly those which are rewarded in the structures of schools (i.e. not appearing 'messy' or losing school materials). The universal value underlying these criteria is that everyone should demonstrate a 
certain ability to be organized (remain still, persevere, navigate social situations, etc.), and those who do not are potentially suffering from a mental disorder.

In depicting certain commonplace behaviors as symptomatic of illness, the authors illustrate deagentilization - the tendency for authors to remove the agency of subjects when describing their actions in texts (van Leeuwen 2009). In the process of describing behaviors that are said to indicate illness, the authors often depict an individual who is not making a conscious decision to, for instance, stop one activity in favor of another. Several examples appear in DSM5 and ICD-10 in which the authors describe actions by removing the agency of the individual, as if they possess no intentionality or free will with regard to their actions:

- Often unable to play or engage in leisure activities quietly (DSM-5; APA 2013, 60, emphasis added)

- Often blurts out an answer before a question has been completed (e.g., completes people's sentences; cannot wait for turn in conversation) (DSM-5; APA 2013, 60, emphasis added)

- Often leaving play activities unfinished (ICD-10; WHO 1993a, 188)

- Over frequent changes between activities when choice is allowed (ICD-10; WHO 1993a, 190)

In these examples, the authors remove any element of decision making on the part of the individual and thereby "encroach[-] on the way a person engages with choice" (Veck 2012, 266). The use of dynamic modal verbs "unable" and "cannot" emphasize the inner state of the observed individual inhibiting her/his agency: the observed actions are not indicative of conscious decision making, but instead of pathological responses to external stimulus. Instead, it is implied that these actions result from an inability of the brain to function properly and regulate supposedly healthy behavior (e.g., playing quietly). Perhaps the most interesting of these examples is the ICD-10 behavior, 'over frequent changes between activities when choice is allowed'. Here, the authors acknowledge that the individual has choice, yet still constructs 'over frequent' exercise of this choice as symptomatic of disorder. One might reasonably suspect that 
an individual might stop with one play activity, consciously choosing to leave it unfinished in order to pursue another more interesting activity. However, by listing this action as symptomatic of an underlying pathology, the authors implicitly discount the ability of the individual to make a conscious decision regarding participation in activities.

\section{Discussion:}

In this article, we have provided insight into the discourse of DSM-5 and ICD-10, showing how certain actions become rearticulated as potential symptoms of mental disorder, namely ADHD/HD. Two of the most striking patterns found in the diagnostic criteria are: the use of vague and broad language, and the value-laden nature of the actions described. First, vague descriptors function as a form of inclusionary criteria; they allow for the disorder to be applied to almost anyone. This is not surprising, given that the breadth and looseness of diagnostic criteria have long been integral to the function of institutional psychiatry, and are seen within the field as a means to guard against potential false-negative diagnoses (Townsend 1982). However, given the significant increase in ADHD/HD diagnoses in many countries, it is likely that the broad criteria are contributing to more diagnoses. The potential of so-called ADHD/HD 'overdiagnosis' is an ongoing controversy. Often overlooked in the debate about the supposed 'correct' frequency of diagnosis is the fact that there is no way to verify that an individual 'has' $\mathrm{ADHD} / \mathrm{HD}$, or conversely, to definitively falsify a diagnosis. What does seem reasonable to conclude is that the broad and vague language used in the manuals allows for a wider range of behaviors to be considered symptoms of mental illness.

Another concern is the value-laden descriptions of actions that are provided by the authors. The British Psychology Society (2011) has criticized the DSM criteria for their valueladen descriptions, arguing that authors medicalize healthy behavior, and that the behaviors reflect normal variation rather than illness. We concur and are alarmed by the DSM-5 and ICD- 
10 authors' narrow view of what constitutes healthy, or acceptable behaviors, such that they prescribe the manner in which individuals should play or sit (i.e., quietly, and with little movement). This is indicative of an ideology of developmentalism, that individuals should develop in psy-scientifically sanctioned ways, behaviorally and academically, in order to be understood as healthy human beings (Baker 1999). A developmentalist worldview compares the subject's behaviors with that of their peers, and more so with the standard of an invisible normal child - a subject implicitly present in the manuals that represents a preference for sameness, and a delineation of preferable behavior and performance (Cooper 2013). The ADHD/HD criteria therefore illustrate a kind of 'dangerous development,' in which the individual's actions threaten the cultural values related to social and academic development (Bailey 2010, 584).

Further, the apparent cultural bias in the diagnostic criteria draws into question whether the criteria meet the manuals' own stipulations for what counts as a disorder:

- Socially deviant behavior (e.g., political, religious, or sexual) and conflicts that are primarily between the individual and society are not mental disorders unless the deviance or conflict results from a dysfunction in the individual... (DSM-V, APA 2013, 20).

- Social deviance or conflict alone, without personal dysfunction, should not be included in mental disorder... (ICD-10, WHO 1993b, 11).

Both manuals stipulate that a disorder cannot be a result of deviant or 'bad' behavior, caused by a social or cultural conflict. It is clear from our analysis that an overwhelming amount of symptoms are based on the deviant actions of children explicitly or implicitly framed as conflicting with social and cultural expectations, those of classrooms in particularly. Therefore, the key question is, do these deviant behaviors result from personal dysfunction?

It is this point - the delineation of individual or personal dysfunction - that reveals a serious shortcoming in the criteria for $\mathrm{ADHD} / \mathrm{HD}$. The authors of these manuals have set up a dichotomy in which personal dysfunction exists as a separate entity, in opposition to social 
conflict. Yet, as our results have shown, the behaviors said to indicate ADHD/HD are so directly intertwined with cultural judgements and social conflicts, that it is difficult to understand how ADHD/HD meets the manuals' own definitions of disorder. Moreover, it is alarming that the authors' specific choices of how they describe the diagnostic criteria mask the culturally constructed elements of the disorder, in favor of promoting a view of personal dysfunction. As we have shown, the authors of the manuals delete other actors or social norms when recontextualizing certain actions as symptomatic behaviors. By deleting the people and norms that surround the person 'with' $\mathrm{ADHD} / \mathrm{HD}$, the authors encourage a pathologizing view that obscures the conflict between the person and the social environment.

At the same time, we also recognize the limitations of critiquing the manuals for promoting a culturally constructed disorder as purely personal dysfunction. Cooper (2008) has advocated for a biopsychosocial understanding of ADHD/HD, in which he understands the disorder as one of a biologically based pre-disposition, mediated by social factors. In doing so, he has argued that criticizing diagnostic criteria for resting on value-laden, culturally-specific judgments about behavior or cognitive norms is insufficient because all "culture reflects the values, attitudes and beliefs of a social group" and taking a culture-free stance is impossible $(2008,465)$. Cooper makes an important point, because any disorders in the DSM-5 or ICD-10, or any illness for that matter, could be critiqued as being value-laden or culturally constructed.

However, what Cooper does not account for is the fluid, shifting nature of cultural judgments about disorders, and the relationship between these judgments and issues of power and politics. Considering our analysis from a critical discourse perspective, clinical manuals do not simply reflect cultural values, attitudes and practices, but instead, construct, maintain, and reproduce them. As Altermark $(2014,1465)$ has stated, "Pathology is not something that science 
discovers" but "something that is constructed with the aid of normative assumptions." This is not to deny that individuals diagnosed with $\mathrm{ADHD} / \mathrm{HD}$ and other disorders may face difficult everyday challenges. However, experiencing difficult challenges is "not tantamount to disease symptoms or a dysfunctional existence" and such experiences do not occur in a social vacuum (Allred 2009, 344). In other words, what Cooper (2008) misses in his reasoned argument for a biopsychosocial understanding of $\mathrm{ADHD} / \mathrm{HD}$, is that the body cannot be separated from the politics that dictate social norms, and which "make some differences appear 'deviant' in the first place" (Altermark 2014, 1467). After all, there are reasons why scientists are more interested in studying the brains and genes of certain individuals, and less so of others.

The social and political impetus behind the ADHD/HD phenomenon brings us to the relationship between discourse and social practices, which is a central aspect of a critical discourse analysis framework. We concur with Bailey (2010) that there is a consistent theme of the classroom in the symptoms; the diagnostic criteria for $\mathrm{ADHD} / \mathrm{HD}$ are built around actions that interfere with everyday classroom practices. Behaviors such as leaving one's seat and wriggling can only be understood as a problem because schools consistently enforce structures and expectations that devalue this behavior. Further evidence that criteria for ADHD/HD symptoms are grounded in the school practice can be found in Sibley and colleagues' (2013) discussion of the implications for recent changes in ADHD criteria in the DSM. The authors write that 'teachers typically work with children in structured group settings that facilitate detection of symptomatic behaviors' $(2013,38)$. The authors implicitly point to the relationship between $\mathrm{ADHD} / \mathrm{HD}$ symptoms and school practices, such that status quo practices of schools increase the likelihood that certain students will manifest ADHD/HD. In doing so, the authors 
unwittingly illustrate the socially constructed nature of ADHD/HD; children's characteristics only become seen as symptomatic of disorder in the context of certain, arbitrary school structures.

We cannot help but wonder that if current classroom structures foster the detection of symptomatic behaviors, then is it also possible that altering such structures could deter the manifestation of such behaviors (or at least how such behaviors are interpreted), such that it would preclude the need for diagnoses in the first place? Sibley and colleagues' assertion illustrates how the discourse of diagnostic criteria protects status quo practices of schools; noncompliance with normative expectations of classrooms is framed as indicating the presence of a mental disorder. In this sense, we understand the discourse in the manuals as reveling less about the individual as it reveals about the dominant 'character of our society and schools' (Veck 2012, 268).

A fundamental purpose of schooling is to instill children with certain knowledge, values, and ways of behaving. Children respond differently to this endeavor. The DSM and ICD authors, and many researchers often depict schools as static environments; children must adjust to the expectations of schools in order for the transmission of knowledge, skills, and values to occur. However, it is important to remember that school structures are themselves human responses and are based on values that can be changed. Rather than using the constructs of clinical manuals to uphold the structures and social norms of schools, we believe that the role of school professionals is to change their practices so that the behaviors these students demonstrate do not create such a conflict to begin with. This involves fostering critical questioning of pre-service and current school professionals as to why, for example, schools "demand passivity, a lack of spontaneity and submission to discipline" (Veck 2012,267). While we acknowledge that it is not in the purview of the manuals to interrogate these issues, nor to suggest practices that would 
prevent or accommodate the behaviors associated with $\mathrm{ADHD} / \mathrm{HD}$, we believe it is also unwarranted that the authors include conflicts with entrenched school structures as indictors of mental illness. As they are written now, the criteria in the manuals justify Slee's $(2014,458)$ concern that "mental illness is in danger for becoming a proxy for difficulties in school."

While it is not our primary intent to suggest changes to the diagnostic criteria for $\mathrm{ADHD} / \mathrm{HD}$, we believe it is worth mentioning some alternatives. Allred (2009) suggested two possibilities in her analysis of Asperger Syndrome, which we find applicable for ADHD/HD. The first is to improve the validity of ADHD/HD by including explicit reference to social values that underpin the diagnostic criteria. Acknowledging the value-laden and socially constructed nature of the disorder would require an evolution of the epistemic guidelines of the psychiatric discourse community (e.g., revisiting the very definition of disorder and its relation to social deviance). Challenging as this may be, it is an ethical imperative; the cultural values that underpin the notion of personal dysfunction and the behaviors associated with disorder must be made explicit to enable the user of these manuals to make informed choices about how they will interpret human behavior. The risk of doing harm to individuals can only be heightened if the criteria for illness consist of cultural values that remain hidden. If made explicit, the criteria would produce a more honest definition of dysfunction and allow for more nuanced conversations about the extent to which these behaviors are understood as universally harmful, such that they reflect the presence of mental illness.

A second possibility is to demedicalize $\mathrm{ADHD} / \mathrm{HD}$. Homosexuality provides one example of demedicalization; behaviors associated with homosexuality were previously considered as characteristic of mental illness, but is no longer listed in the DSM or ICD (Allred 2009). However, there are significant deterrents towards achieving demedicalization, because 
diagnostic labels such as $\mathrm{ADHD} / \mathrm{HD}$ are legal and paralegal entities that are used to attain social support and as means to navigate through social institutions. Additionally, diagnostic explanations provide an individual with therapeutic value in terms self-empathy and selfacceptance among other functions of recognition the label affords (Honkasilta, 2016, Emerald \& Carpenter 2010).

\section{Conclusion}

While we have used the manuals' terminology 'disorder' to discuss ADHD/HD throughout this article, we conclude with considering the relationship between the discourse in the manuals and the concept of disability. As Garland-Thompson (2012) argues, disability gains its meaning in part because it resists or conflicts with aspects of modern society, such as the expectation to take action in the present that will ensure a trajectory leading to future outcomes. In contrast, disability "represents aspects of the human condition that are unpredictable, unstable, and unexpected: in short, contingency itself" (Garland-Thompson 2012, 340). The manuals we have analyzed are filled with examples of actions that are unpredictable and inconsistent, and which disregard future outcomes in favor of the present moment (e.g., so-called impulsive behavior). The diagnostic criteria themselves symbolize a form of anxiety over bodies that do not adhere to temporal expectations and a desire for predictability in modern culture. The overarching belief behind the discourse is that it is desirable for these behaviors to be eliminated. The manuals in effect disqualify certain actions from being considered indicators of healthy behavior.

However, if actions can be recontextualized in this way, then they can be further recontextualized and imbued with new meaning. Borrowing Garland-Thompson's (2012) notion of conserving disability - seeing characteristics as benefits instead of deficits that should be 
eliminated - we ask: how might we reconsider the behaviors associated with $\mathrm{ADHD} / \mathrm{HD}$, so that they are seen as valuable and worthy of conservation? Without romanticizing behaviors deemed and/or experienced as challenging, it is reasonable to consider how such behaviors may be healthy reactions to inaccessible environments, rather than signs of individual pathology (Veck 2012). We might therefore consider the valuable resources offered by individuals who display these characteristics; as educators, the actions described in the manuals alert us the limits in our own ability to respond to the diversity of children. Challenging as these characteristics may be, they hold the promise of disrupting the status quo and demanding new ways of approaching schooling and parenting.

The characteristics force us to consider what we can learn and how we will respond to children like Alex from the opening of this article, who might play noisily and forgo future rewards in favor of instant gratification (e.g., Graham 2010b). Children and adolescents diagnosed with mental disorders account for their actions, agency, and moral selves in ways that contradict psychiatric literature which defines these disorders (O’Neil 2008; Honkasilta, Vehmas, \& Vehkakoski, 2016), and which promotes a clinical focus that often foregrounds their limitations instead of unique capacities (Rapley, 2004). When taken out of the context of a discourse of pathology (e.g., clinical manuals) the actions associated with ADHD/HD hold the potential to serve as an impetus for rethinking entrenched school practices and expanding our capacity to respond to diversity. These behaviors, we believe, are more worthy of conservation, than prevention or elimination.

\section{References}

Abbey, E., and J Valsiner. 2005. "The making of somebody else: Diagnostic labels, educational practices, and meaning-making." European Journal of School Psychology 3 (1): 83-99 
Allred, S. 2009. Reframing Asperger syndrome: lessons from other challenges to the Diagnostic and statistical manual and ICIDH approaches. Disability \& Society, 24(3): 343-355.

Altermark, N. 2014. The ideology of neuroscience and intellectual disability: reconstituting the 'disordered' brain. Disability \& Society, 29, (9): 1460-1472.

Al-Yagon, M., Cavendish, W., Cornoldi, C., Fawcett, A. J., Grünke, M., Hung, L. Y., ... \& Margalit, M. 2013. "The Proposed Changes for DSM-5 for SLD and ADHD International PerspectivesAustralia, Germany, Greece, India, Israel, Italy, Spain, Taiwan, United Kingdom, and United States.” Journal of Learning Disabilities, 46, (1): 58-72.

American Psychiatric Association (APA). 2013. Diagnostic and Statistical Manual of Mental Disorders: DSM-5. Washington, DC: American Psychiatric Association

Antrop, I., H. Roeyers, P. Van Oost, and A. Buysse. 2000. "Stimulation seeking and hyperactivity in children with ADHD." Journal of Child Psychology and Psychiatry 41, (2): 225-231.

Antrop, I., H. Roeyers, and L. De Baecke. 2005. "Effects of time of day on classroom behaviour in children with ADHD." School Psychology International 26, (1): 29-43

Baker, B. 1999. "The dangerous and the good? Developmentalism, progress, and public schooling." American Educational Research Journal 36, (4): 797-834.

Bailey, S. 2010. "The DSM and the dangerous school child." International Journal of Inclusive Education 14 (6): 581-592.

Barkley, R. A. 2002. "International Consensus Statement on ADHD.” Clinical Child and Family Psychology Review 5 (2): 89 - 111.

Barkley, R.A. 2004. "Critique or misrepresentation? A reply to Timimi et al." Clinical Child and Family Psychology Review, 7(1), 65-69.

Barkley, R. A. 2013 Taking charge of ADHD: The complete, authoritative guide for parents. Guilford press.

The British Psychological Society. 2011. Response to the American Psychiatric Association: DSM-5 Development. Available at: http://apps.bps.org.uk/_publicationfiles/consultationresponses/DSM-5\%202011\%20-\%20BPS\%20response.pdf [accessed 11 May 2015].

Brown, T. E. 2013. A new understanding of ADHD in children and adults: Executive function impairments. Routledge.

Children and Adults with ADHD (CHADD). 2015. "Myths and misunderstandings." http://www.chadd.org/Understanding-ADHD/About-ADHD/Myths-and-Misunderstandings.aspx 
Conrad, P. "The discovery of hyperkinesis: Notes on the medicalization of deviant behavior." 1975. Social problems 23, (1): 12-21.

Cooper, P. 2008. Like alligators bobbing for poodles? A critical discussion of education, ADHD and the biopsychosocial perspective. Journal of Philosophy of Education, 42(3-4): 457-474.

Cooper, H. 2013. The oppressive power of normalcy in the lives of disabled children: Deploying history to denaturalize the notion of the 'normal child.' In T. Curran \& K. Runswick-Cole (Eds.), Disabled Children's Childhood Studies (pp. 136-151). Palgrave Macmillan

Cosgrove, L., S Krimsky, M Vijayaraghavan, and L Schneider. 2006. "Financial ties between DSM-IV panel members and the pharmaceutical industry." Psychotherapy and Psychosomatics 75, (3): $154-160$

Davis, L. J. 2009. Obsession: A history. University of Chicago Press.

Emerald, E. \& Carpenter, L. 2010. ADHD, mothers, and the politics of school recognition. In L. J. Graham (Ed.), (De)Constructing ADHD: critical guidance for teachers and teacher educators (pp. 99-118). New York: Peter Lang.

Fairclough, N. 1995. Critical Discourse Analysis: The Critical Study of Language, London: Longman.

Faraone, S.V. 2005. "The scientific foundation for understanding attention deficit/hyperactivity disorder as a valid psychiatric disorder." European Child \& Adolescent Psychiatry, 14(1), 1-10.

Freedman, J. E. (2016). An analysis of the discourses on attention deficit hyperactivity disorder (ADHD) in US special education textbooks, with implications for inclusive education. International Journal of Inclusive Education, 20(1), 32-51.

Galves, A.O., Walker, D., Cohen, D., Schneider, K.J., Greening, T., Karon, B., Dunlap, M., Wetzel, N.A., Friedman, H., Duncan, B., \& Johnson, T. 2003. A letter to APA by 11 psychologists. Available at: http://psychrights.org/articles/replytorubenstein.pdf

Garland-Thomson, R. 2012 "The case for conserving disability." Journal of bioethical inquiry 9, no. 3: 339-355.

Graham, L. (2007). Speaking of "disorderly" objects: A poetics of pedagogical discourse, Discourse: Studies in the Cultural Politics of Education, 28:(1), 1-20, doi:10.1080/01596300601073044

Graham, L. J. ed. 2010a. (De) constructing ADHD: critical guidance for teachers and teacher educators. Peter Lang.

Graham, L.J. 2010b. Thinking pedagogically. In Graham, L.J. (Ed). (De)Constructing ADHD: critical guidance for teachers and teacher educators (pp. 205-220). New York: Peter Lang. 
Hacking, I. 1999. The social construction of what?. Harvard University Press.

Honkasilta, J. (2016). Voices behind and beyond the label: The master narrative of ADHD (de)constructed by diagnosed children and their parents. Doctoral thesis, Jyväskylä Studies in Education, Psychology and Social Research 553. Jyväskylä: Jyväskylä University Printing House

Honkasilta, J., Vehmas, S., \& Vehkakoski, T. (2016). Self-pathologizing, selfcondemning, selfliberating: youths' accounts of their ADHD-related behavior. Social Science \& Medicine, 150, 248-255. Doi:10.1016/j.socscimed.2015.12.030

Jureidini, J. 2002. "Does the International Consensus Statement on ADHD Leave Room for Healthy Skepticism?" European Child \& Adolescent Psychiatry 11(5): 240.

Kirk, S. A., and H. Kutchins. 1992 The selling of DSM: The rhetoric of science in psychiatry. Transaction Publishers.

Lahey, B. B., W. E. Pelham, A. Chronis, G. Massetti, H. Kipp, A. Ehrhardt, and S. S. Lee. 2006. "Predictive validity of ICD-10 hyperkinetic disorder relative to DSM-IV attentiondeficit/hyperactivity disorder among younger children." Journal of Child Psychology and Psychiatry 47, (5): 472-479

Levy, F., D. A. Hay, M. Mcstephen, C. Wood, and I. Waldman. 1997. "Attention-deficit hyperactivity disorder: a category or a continuum? Genetic analysis of a large-scale twin study." Journal of the American Academy of Child \& Adolescent Psychiatry 36, (6):737-744

Lee, S., I., Russell J. Schachar, S. X. Chen, T. J. Ornstein, A. Charach, C. Barr, and A. Ickowicz. 2008. "Predictive validity of DSM-IV and ICD-10 criteria for ADHD and hyperkinetic disorder." Journal of child psychology and Psychiatry 49, (1): 70-78

Luke, A.. 1995. "Text and discourse in education: An introduction to critical discourse analysis." Review of research in education: $3-48$

Lloyd, G., J. Stead, and D. Cohen, eds. 2006 Critical new perspectives on ADHD. Routledge.

Moloney, P. 2010. 'How can a chord be weird if it expresses your soul?' Some critical reflections on the diagnosis of Aspergers syndrome. Disability \& Society, 25(2): 135-148.

Moncrieff, J., and S. Timimi. 2010. "Is ADHD a valid diagnosis in adults?" BMJ, 340

Nigg, J. T. 2006. What causes ADHD?: Understanding what goes wrong and why. Guilford Press.

O’Neil, S. 2008. The meaning of autism: beyond disorder. Disability \& Society, 23(7): 787-799.

Rapley, M. 2004. The social construction of intellectual disability. Cambridge University Press. 
Rogers, R. (Ed.) 2004. An introduction to critical discourse analysis in education. Routledge

Saul, R. 2014. ADHD does not exist. Harper Collins.

Sharkey, L. and M. Fitzgerald. "The history of attention deficit hyperactivity disorder." In Handbook of attention deficit hyperactivity disorder, edited by Fitzgerald, M., M. Bellgrove, and M. Gill, 3-11. John Wiley \& Sons.

Sibley, M. H., J. G. Waxmonsky, J. A. Robb, and W. E. Pelham. 2013. "Implications of Changes for the Field ADHD." Journal of learning disabilities 46, (1) (2013): 34-42

Slee, R.. 2014. "Evolving theories of student disengagement: a new job for Durkheim's children?." Oxford Review of Education 40, (4): 446-465.

Tannock, R. 2013. "Rethinking ADHD and LD in DSM-5 Proposed Changes in Diagnostic Criteria." Journal of learning disabilities 46, (1): 5-25

Tomlinson, S. 1982. A Sociology of Special Education. Routledge

Timini, S. 2004. "A Critique of the International Consensus Statement on ADHD." Clinical Child and Family Psychology Review 7, (1): 59 - 63.

Timimi, S., and J. Leo, eds. 2009. Rethinking ADHD: From Brain to Culture. Basingstoke: Palgrave Macmillan

Timimi, S. and Taylor, E., 2004. "ADHD is best understood as a cultural construct." The British Journal of Psychiatry, 184, (1), 8-9.

Townsend, J. M. 1982. "Psychiatric versus social factors: An attempt at integration." Human Relations $35,(9): 785-804$.

United States Office of Special Education Programs. 2003. Identifying and Treating Attention Deficit and Hyperactivity Disorder: A Resource for School and Home. Washington, DC: U.S. Office of Special Education Programs, U.S. Dept. of Education.

Van Dijk, T. A. 2008. "Discourse studies and education." Applied linguistics 2, (1): 1-26.

Van Dijk, T. A. 2014 Discourse and knowledge: A sociocognitive approach. Cambridge University Press.

van leeuwen, T. 2009. "Discourse as the Recontextualization of Social Practice: A Guide." In Methods for critical discourse analysis, edited by Ruth Wodak and Michael Meyer, 144-161. Sage

Veck, W. 2012. Reflecting on attention-deficient hyperactivity disorder and disablement in education with Eric Fromm. Disability \& Society, 27(2): 263-275. 
Whitely, M. 2015. "Attention deficit hyperactive disorder diagnosis continues to fail the reliability and validity tests." Australian and New Zealand Journal of Psychiatry (2015) DOI: 0004867415579921

Widdowson, H. G. 1995 "Discourse analysis: a critical view." Language and literature 4, (3): 157-172.

Wodak, R., and M. Meyer. 2009. "Critical Discourse Analysis: History, Agenda, Theory and Methodology." In Methods for critical discourse analysis, edited by Ruth Wodak and Michael Meyer, 1-33. Sage.

World Health Organization. 1993a. The international classification of mental and behavioural disorders: Diagnostic criteria for research. $\left(10^{\text {th }}\right.$ revision). Geneva: World Health Organization.

World Health Organization. 1993b. The international classification of mental and behavioural disorders: Clinical descriptions and diagnostic guidelines. (10 th revision). Geneva: World Health Organization.

Appendix A. Diagnostic Criteria for Attention-Deficit/Hyperactivity Disorder in DSM-V

A persistent pattern of inattention and/or hyperactivity-impulsivity that interferes with functioning or development, as characterized by (1) and/or (2):

1. Inattention: Six (or more) of the following symptoms have persisted for at least 6 months to a degree that is inconsistent with the developmental level and that negatively impacts directly on social and academic/occupational activities:

a. Often fails to give close attention to details or makes careless mistakes in schoolwork, at work, or during other activities (e.g., overlooks or misses details, work is inaccurate).

b. Often has difficulty sustaining attention in tasks or play activities (e.g., had difficulty remaining focused during lectures, conversations, or lengthy reading).

c. Often does not seem to listen when spoken to directly (e.g., mind seems elsewhere, even in the absence of any obvious distraction).

d. Often does not follow through on instructions and fails to finish schoolwork, chores, or duties in the workplace (e.g., starts tasks but quickly loses focus and is easily sidetracked).

e. Often has difficulty organizing tasks and activities (e.g., difficulty managing sequential tasks; difficulty keeping materials and belongings in order; messy, disorganized work; has poor time management; fails to meet deadlines).

f. Often avoids, dislikes, or is reluctant to engage in tasks that require sustained mental effort (e.g., schoolwork or homework; for older adolescents and adults, preparing reports, completing forms, reviewing lengthy papers). 
g. Often loses things necessary for tasks or activities (e.g. school materials, pencils, books, tools, wallets, keys, paperwork, eyeglasses, mobile phones).

h. Is often easily distracted by extraneous stimuli (for older adolescents and adults, may include unrelated thoughts).

i. Is often forgetful in daily activities (e.g., doing chores, running errands; for older adolescents and adults, returning calls, paying bills, keeping appointments).

2. Hyperactivity and impulsivity: Six (or more) of the following symptoms have persisted for at least 6 months to a degree that is inconsistent with developmental level and that negatively impacts directly on social and academic/occupational activities:

a. Often fidgets with or taps hands or feet or squirms in seat.

b. Often leaves seat in situations when remaining seated is expected (e.g., leaves his or her place in the classroom, in the office or other workplace, or in other situations that require remaining in place).

c. Often runs about or climbs in situations where it is inappropriate. (Note: In adolescents or adults, may be limited to feeling restless.)

d. Often unable to play or engage in leisure activities quietly.

e. Is often "on the go," acting as if "driven by a motor" (e.g., is unable to be or uncomfortable being still for extended time, as in restaurants, meetings; may be experienced by others as being restless or difficult to keep up with).

f. Often talks excessively.

g. Often blurts out an answer before a question has been completed (e.g., completes people's sentences; cannot wait for turn in conversation).

h. Often has difficulty waiting his or her turn (e.g., while waiting in line).

i. Often interrupts or intrudes on others (e.g., butts into conversations, games, or activities; may start using other people's things without asking or receiving permission; for adolescents and adults, may intrude into or take over what others are doing).

Appendix B. Diagnostic criteria for Hyperkinetic Disorder in ICD-10

Demonstrable abnormality of attention, activity and impulsivity at home, for the age and developmental level of the child, as evidenced by (1), (2) and (3):

1. At least three of the following attention problems:

a. Short duration of spontaneous activities;

b. Often leaving play activities unfinished;

c. Over-frequent changes between activities;

d. Undue lack of persistence at tasks set by adults;

e. Unduly high distractibility during study e.g. homework or reading assignment;

2. Plus at least three of the following activity problems:

a. Very often runs about or climbs excessively in situations where it is inappropriate; seems unable to remain still; 
b. Markedly excessive fidgeting \& wriggling during spontaneous activities;

c. Markedly excessive activity in situations expecting relative stillness (e.g. mealtimes, travel, visiting, church);

d. Often leaves seat in classroom or other situations when remaining seated is expected;

e. often has difficulty playing quietly.

3. Plus at least one of the following impulsivity problems:

a. Often has difficulty awaiting turns in games or group situations;

b. Often interrupts or intrudes on others (e.g. butts in to others' conversations or games);

c. Often blurts out answers to questions before questions have been completed.

Demonstrable abnormality of attention and activity at school or nursery (if applicable), for the age and developmental level of the child, as evidenced by both (1) and (2):

1. At least two of the following attention problems:

a. Undue lack of persistence at tasks;

b. Unduly high distractibility, i.e. often orienting towards extrinsic stimuli;

c. Over-frequent changes between activities when choice is allowed;

d. Excessively short duration of play activities;

2. And by at least three of the following activity problems:

a. Continuous (or almost continuous) and excessive motor restlessness (running, jumping, etc.) in situations allowing free activity;

b. Markedly excessive fidgeting and wriggling in structured situations;

c. Excessive levels of off-task activity during tasks;

d. Unduly often out of seat when required to be sitting;

e. Often has difficulty playing quietly. 